\title{
Assessment of low-flow, low-gradient aortic stenosis: multimodality imaging is the key to success
}

\author{
Marie-Annick Clavel, DVM, PhD; Philippe Pibarot*, DVM, PhD, FACC, FAHA, FESC, FASE \\ Institut Universitaire de Cardiologie et de Pneumologie de Québec/Québec Heart \& Lung Institute, Laval University, Québec, \\ QC, Canada
}

This paper also includes accompanying supplementary data published online at: http://www.pcronline.com/eurointervention/U_issue/8

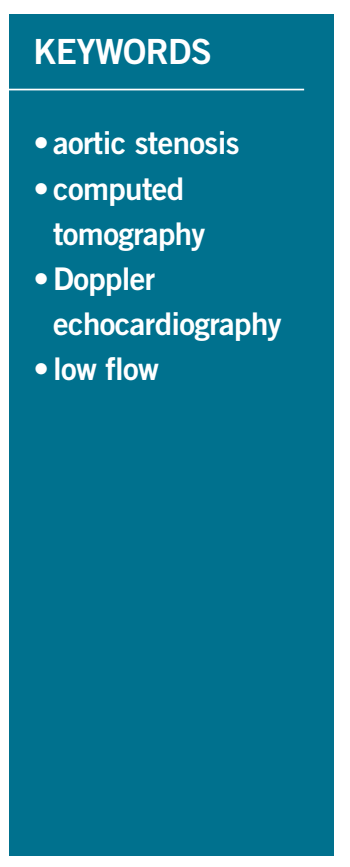

\begin{abstract}
In patients with aortic stenosis (AS), a low-flow state may occur with reduced LV ejection fraction (LVEF) (i.e., classic low flow) or with preserved LVEF (i.e., paradoxical low flow) and it is often associated with low gradient because the gradient is highly flow-dependent. Low-flow, low-gradient (LF-LG) AS is a frequent clinical entity generally associated with worse outcomes. A multimodality imaging approach, including comprehensive resting echocardiography, dobutamine stress echocardiography (DSE), and multidetector computed tomography (MDCT), is the key to successful management of patients with LF-LG AS, who represent a highly challenging subset from both a diagnostic and a therapeutic standpoint. DSE and quantification of aortic valve calcification by MDCT provide important information that is crucial to differentiate true-severe from pseudo-severe AS and therefore select the most appropriate therapy (i.e., AVR vs. medical). The assessment of LV flow reserve by DSE is useful to stratify the operative risk and guide decision making between surgical and transcatheter AVR. Other imaging biomarkers, such as the global LV longitudinal strain measured during DSE or the amount of myocardial fibrosis assessed by cardiac magnetic resonance imaging, may provide incremental information for risk stratification and therapeutic management in LF-LG AS, but additional studies are needed to validate and refine these emerging biomarkers further.
\end{abstract}

\footnotetext{
*Corresponding authors: Québec Heart \& Lung Institute, 2725 Chemin Sainte-Foy, Québec, QC, G1V 4G5, Canada. E-mail:philippe.pibarot@med.ulaval.ca
} 


\section{Introduction}

Most patients with severe aortic stenosis (AS) present with a small aortic valve area $\left(\mathrm{AVA}<1 \mathrm{~cm}^{2}\right)$ and a high mean transvalvular gradient $(\mathrm{MG} \geq 40 \mathrm{mmHg})^{1}$. If such patients are symptomatic or have a reduced LV ejection fraction (LVEF), aortic valve replacement (AVR) is recommended (Class I) ${ }^{2,3}$. However, in about one third of patients with AS, there is a discordance among echocardiographic or cardiac catheterisation markers of AS severity, the most frequent being an AVA $<1 \mathrm{~cm}^{2}$ and a $\mathrm{MG}<40 \mathrm{mmHg}$ (or peak aortic jet velocity, $V \max <4 \mathrm{~m} / \mathrm{s})^{4-6}$. This discordance may raise uncertainty about the actual severity of the stenosis and thus about the indication of AVR. This AVA (small) - gradient (low) discordance may be related to several factors including: i) measurement errors, ii) small body surface area, iii) inherent discrepancy in the AVA and gradient cut points proposed in the guidelines to define severe stenosis, and/or iv) the presence of a low-flow state ${ }^{7-10}$. A low-flow state may occur with reduced LVEF (i.e., classic low flow) or with preserved LVEF (i.e., paradoxical low flow) and it is often associated with low gradient and worse outcomes ${ }^{5,8,11-13}$. Hence, low-flow, low-gradient (LF-LG) AS is a highly challenging entity from both a diagnostic and a therapeutic standpoint. The purpose of this article is to describe the key role of multimodality imaging, and in particular of Doppler echocardiography and multidetector computed tomography (MDCT) for the assessment of stenosis severity, the risk stratification, and the therapeutic management in patients with LF-LG AS.

\section{Different patterns of low-flow, low-gradient AS}

Low flow is generally defined by a stroke volume indexed to body surface area $<35 \mathrm{~mL} / \mathrm{m}^{2}$ and/or a cardiac index $<31 / \mathrm{min} / \mathrm{m}^{2}$ and low gradient by a $\mathrm{MG}<40 \mathrm{mmHg}^{2,3}$. There are two main different patterns of LF-LG AS: classic and paradoxical LF-LG AS (Figure 1, Table 1, Moving image 1). Classic LF-LG occurs in 5 to $10 \%$ of patients with $\mathrm{AS}^{14,15}$ and it is characterised by a reduced
LVEF and often enlarged LV cavity (Figure 1, Table 1, Moving image 2) ${ }^{13,16-19}$. Patients with this entity are more often men and frequently have concomitant coronary artery disease $\mathrm{e}^{20}$. Paradoxical LF-LG AS occurs in 5 to $20 \%$ of the AS population and, as opposed to classic LF-LG, this entity is characterised by a preserved LVEF and a small LV cavity with pronounced concentric remodelling (Figure 1, Table 1, Moving image 3$)^{4,8,9,21}$. This entity is more frequent in women and is often associated with concomitant arterial hypertension. In patients with classic LF-LG AS, the low stroke volume is mainly due to depressed LV systolic function, whereas in paradoxical LF-LG it is predominantly related to a restrictive physiology (Table 1). Furthermore, although patients with paradoxical LF-LG have a preserved LVEF, their LV systolic longitudinal is typically reduced, particularly in the basal segments, and this phenomenon further contributes to reducing stroke volume ${ }^{21,22}$. Besides LV systolic/diastolic dysfunction, other concomitant factors may also cause or worsen a low-flow state in AS patients, including mitral regurgitation, mitral stenosis, tricuspid regurgitation, atrial fibrillation, constrictive pericarditis, etc.

The first essential step in the evaluation of patients with LF-LG AS is to rule out measurement errors (Figure 2). Particular attention should be paid to the measurement of stroke volume in the LV outflow tract, since this parameter is used to identify the presence of low flow (i.e., stroke volume index $<35 \mathrm{~mL} / \mathrm{m}^{2}$ ) and also to calculate the $\mathrm{AVA}^{23}$. Hence, an underestimation of stroke volume could lead the echocardiographer to conclude falsely that the patient has a LF-LG severe AS, whereas in fact he or she has moderate AS with normal flow. Proper confirmation of the presence and type of LF-LG (classic versus paradoxical) also requires the identification of the Doppler echocardiographic features presented in Table 1 as well as the factor(s) responsible for the low-flow state. A comprehensive Doppler echocardiographic exam is thus essential for diagnosis and characterisation of LF-LG AS as well as for the identification of the causative factors.

Table 1. Comparison of Doppler echocardiographic features in the two patterns of low-flow, low-gradient AS versus normal-flow, high-gradient AS.

\begin{tabular}{|c|c|c|c|}
\hline & $\begin{array}{l}\text { Preserved LVEF normal-flow, } \\
\text { high-gradient AS (50-70\%) }\end{array}$ & $\begin{array}{c}\text { Preserved LVEF (paradoxical) } \\
\text { low-flow, low-gradient AS (5-20\%) }\end{array}$ & $\begin{array}{l}\text { Low LVEF (classic) low-flow, } \\
\text { low-gradient AS (5-10\%) }\end{array}$ \\
\hline Aortic valve area $\left(\mathrm{cm}^{2}\right)$ & $<1.0$ & $<1.0$ & $<1.0$ \\
\hline Aortic valve area index $\left(\mathrm{cm}^{2} / \mathrm{m}^{2}\right)$ & $<0.6$ & $<0.6$ & $<0.6$ \\
\hline Mean gradient $(\mathrm{mmHg})$ & $\geq 40$ & $<40$ & $<40$ \\
\hline Doppler velocity index & $<0.25$ & $<0.25$ & $<0.25$ \\
\hline LV end-diastolic diameter (mm) & $45-55$ & $<47$ & $>50$ \\
\hline Relative wall thickness & $>0.43$ & $>0.50$ & $0.35-0.55$ \\
\hline Diastolic dysfunction & Mild/moderate & Moderate/severe & Moderate/severe \\
\hline LV ejection fraction (\%) & $>50 \%$ & $>50 \%$ & $<50 \%$ \\
\hline Global longitudinal strain (\%) & $15-20$ & $<15$ & $<15$ \\
\hline Stroke volume index $\left(\mathrm{mL} / \mathrm{m}^{2}\right)$ & $>35$ & $<35$ & $<35$ \\
\hline Mean flow rate $(\mathrm{mL} / \mathrm{s})$ & $>200$ & $<200$ & $<200$ \\
\hline
\end{tabular}




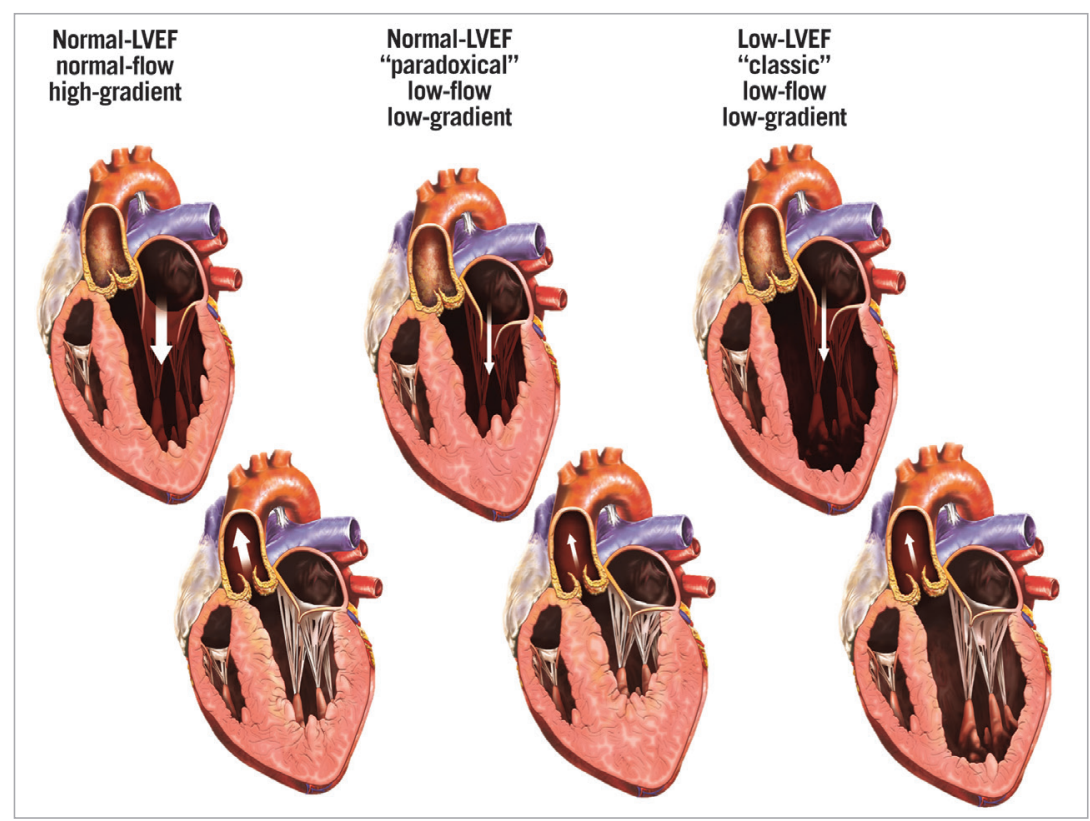

Figure 1. Different patterns of severe AS according to flow, gradient, and LV geometry. Top panels: diastole. Bottom panels: systole. Reproduced with permission ${ }^{19}$.

\section{Assessment of stenosis severity}

In the setting of a low-flow state, it is often difficult to separate patients with true-severe AS (TS AS) from those with pseudosevere AS (PS AS), i.e., with a reduced aortic opening due to limited flow in the setting of only mild to moderate aortic valve obstruction $^{13,24-27}$. This distinction is essential since patients with TS AS are the ones who may benefit from AVR, whereas the patients with PS AS may not benefit from this intervention and should rather be treated medically ${ }^{27,28}$. Approximately one third of patients with LF-LG AS have PS AS and the proportion is similar in patients with classic versus paradoxical LF-LG ${ }^{18,27-29}$.

Dobutamine stress echocardiography (DSE) with low-dose (up to $20 \mu \mathrm{g} / \mathrm{kg} / \mathrm{min}$ ) protocol has been shown to be useful to differentiate TS from PS AS in patients with classic LF-LG

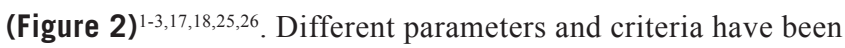
proposed in the literature to identify TS AS including a peak stress $\mathrm{MG} \geq 30$ or $40 \mathrm{mmHg}$, a peak stress AVA $<1.0$ or $1.2 \mathrm{~cm}^{2}$ and/or an increase in AVA $<0.2$ or $0.3 \mathrm{~cm}^{2} 17,25,26$. In the ESC/ EACTS guidelines ${ }^{3}$, TS AS is considered to be present when there are small changes in AVA (increase $<0.2 \mathrm{~cm}^{2}$ and remaining $<1.0 \mathrm{~cm}^{2}$ ) with increasing flow rate but a significant increase in gradients ( $\mathrm{MG}>40 \mathrm{mmHg}$ ). In the $2014 \mathrm{ACC} / \mathrm{AHA}$ guidelines ${ }^{2}$, TS AS is defined by a $\mathrm{MG}>40 \mathrm{mmHg}$ (or $\mathrm{V}_{\text {Peak }} \geq 4 \mathrm{~m} / \mathrm{s}$ ) with an AVA $\leq 1.0 \mathrm{~cm}^{2}$ at any DSE stage. However, given that all parameters of stenosis severity are flow-dependent, the magnitude of their augmentation during DSE may vary greatly depending on the extent of LV flow reserve (i.e., the increase in flow during DSE $)^{30}$. Hence, in patients with minimal flow reserve, the AVA (small) - gradient (low) discordance may persist at the end of DSE and the stenosis severity therefore remains uncertain. In such patients with persisting discordance at DSE, it could be useful to calculate the projected AVA at normal flow rate (i.e., $250 \mathrm{~mL} / \mathrm{s}$ ) using the following equation ${ }^{29}$ :

$$
\text { Projected AVA }=\mathrm{AVA}_{\text {Rest }}+\frac{\mathrm{AVA}_{\text {Peak }}-\mathrm{AVA}_{\text {Rest }}}{\left(\mathrm{Q}_{\text {Peak }}-\mathrm{Q}_{\text {Rest }}\right)} \times\left(250-\mathrm{Q}_{\text {Rest }}\right)
$$

where $\mathrm{AVA}_{\text {Rest }}$ and $\mathrm{AVA}_{\text {Peak }}$ are AVA at rest and peak DSE and $\mathrm{Q}_{\text {Rest }}$ and $\mathrm{Q}_{\text {Peak }}$ are transvalvular flow rate (stroke volume divided by ejection time) at rest and peak DSE. A projected AVA $\leq 1.0 \mathrm{~cm}^{2}$ suggests the presence of TS AS. This new parameter has the advantage of being standardised for flow rate, and it has been shown to predict actual stenosis severity and clinical outcomes better in patients with classic LF-LG AS ${ }^{18,27,29,30}$. In contrast, aortic valve resistance does not appear to offer any significant advantage in these patients given that it is, in fact, more flow-dependent than $\mathrm{AVA}^{31}$. Dobutamine stress catheterisation can also be used to differentiate TS from PS $\mathrm{AS}^{26}$ but it is more invasive than DSE and is also subject to technical pitfalls and measurement errors. DSE is thus the preferred approach to confirm stenosis severity in patients with classic LF-LG AS (Figure 2). A recent study also showed that DSE or exercise stress echocardiography can be used in patients with paradoxical LF-LG AS and the same parameters and criteria (including projected AVA) can be applied in these patients (Figure 2) ${ }^{27}$. However, DSE should not be used in patients with severe LV restrictive physiology, which is frequently found in patients with paradoxical LF-LG AS. Exercise stress echocardiography may be used in patients who are asymptomatic or have mild equivocal symptoms. The DSE parameters and criteria presented above to differentiate TS from PS AS can also be applied for exercise stress echocardiography.

In a significant proportion ( 20 to $30 \%$ ) of patients with classic or paradoxical LF-LG AS, DSE is not feasible due to contraindications 


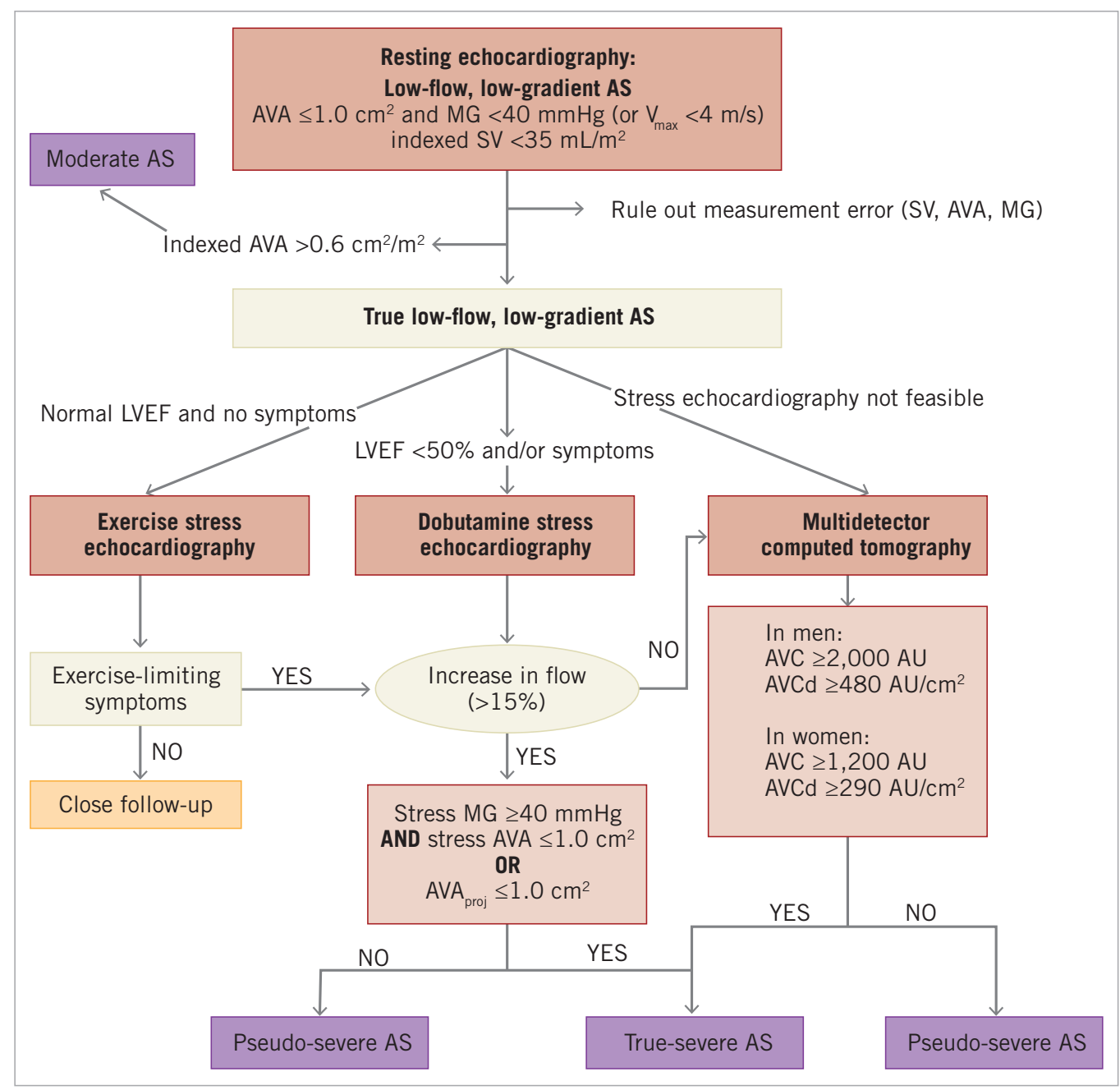

Figure 2. Algorithm for the assessment of stenosis severity in patients with low-flow, low-gradient aortic stenosis. When the increase in mean flow rate (stroke volume/LV ejection time) is $<15 \%$, the results of DSE with regard to stenosis severity (AVA, MG, and projected AVA) are generally inconclusive. AS: aortic stenosis; AVA: aortic valve area; AVC: aortic valve calcification; AVCd: AVC density, i.e., AVC divided by aortic annulus cross-sectional area, $L V E F$ : left ventricular ejection fraction; $M G$ : mean gradient; SV: stroke volume

(complex ventricular arrhythmia, rapid atrial arrhythmia, unstable angina, severe restrictive physiology, etc.) or it is inconclusive due to absence of flow reserve or poor image quality. In such patients, quantification of aortic valve calcification (AVC) by MDCT can be used to corroborate stenosis severity (Figure 2). Indeed, AVC has been shown to correlate well with AS haemodynamic severity ${ }^{6,32,33}$. However, this relationship is gender-dependent: women reach haemodynamically severe AS with a lower amount of AVC compared to men, even after accounting for body surface area and aortic annulus cross-sectional area ${ }^{6,34}$. It is thus important to use lower AVC cut-point values in women (AVC $\geq 1,200 \mathrm{AU}$ ) than in men (AVC $\geq 2,000 \mathrm{AU}$ ) to identify severe $\mathrm{AS}^{6}$. The AVC can also by indexed to the cross-sectional area of the aortic annulus to obtain the "AVC density" (AVCd), and the threshold values for severe stenosis are: $\mathrm{AVCd} \geq 290 \mathrm{AU} / \mathrm{cm}^{2}$ in women and $\mathrm{AVCd} \geq 480 \mathrm{AU} / \mathrm{cm}^{2}$ in men ${ }^{6}$. The measurement of AVC by MDCT has several advantages, including the fact that it is highly feasible, simple, reproducible, and accurate. More importantly, this parameter is not influenced by flow or haemodynamics and therefore, as opposed to all other modalities including Doppler echocardiography, cardiac magnetic resonance (CMR), and cardiac catheterisation, it does not require dobutamine (or other) stress agent to differentiate TS from PS AS in patients with classic or paradoxical LF-LG. Hence, AVC by MDC provides a valuable alternative to DSE in these patients when the latter is not feasible or inconclusive (Figure 2). MDCT also has some limitations including: i) the exposure to ionising radiation; ii) the variability of the AVC measurements depending on the image acquisition/analysis system, software, and protocol; and iii) the occurrence (even if low) of false negative (i.e., low AVC despite TS AS) or false positive (i.e., high AVC despite PS AS) cases. DSE and MDCT are thus complementary imaging modalities, which allow the confirmation of stenosis severity in patients with LF-LG AS (Figure 2).

Like echocardiography and CMR, MDCT allows the measurement of the anatomic valve orifice area by planimetry. However, due to the flow contraction phenomenon, the anatomic AVA often 
overestimates the Doppler-derived effective AVA, which is the main determinant of the transvalvular gradient and LV pressure overload. Nonetheless, if, in a patient with a small $\left(<1.0 \mathrm{~cm}^{2}\right)$ effective AVA, 2D echocardiography, CMR or MDCT reveals a large anatomic AVA $\left(>1.5 \mathrm{~cm}^{2}\right)$, one should suspect an error in the measurement of the effective AVA by Doppler echocardiography. As for the effective AVA, the anatomic AVA may be pseudo-severe, and thus dobutamine stress is required to confirm stenosis severity.

\section{Risk stratification}

It is well known that depressed LVEF is a major predictor of mortality in the general AS population, regardless of the type of treatment - conservative or AVR ${ }^{11,13,20}$. Recently, low flow (i.e., stroke volume index $\leq 35 \mathrm{~mL} / \mathrm{m}^{2}$ ) has also been shown to be a powerful risk factor in patients with AS, which is possibly stronger than $\mathrm{LVEF}^{12,20,35,36}$. A low gradient ( $\mathrm{MG}<40 \mathrm{mmHg}$ ) has been reported to be a predictor of post-procedural mortality in the subset of patients undergoing surgical or transcatheter AVR, but recent studies suggest that this risk apparently associated with low gradient is, in large part, due to the concomitant presence of low flow ${ }^{12,35-37}$.

In patients with classic LF-LG, very low resting gradient (MG $<20 \mathrm{mmHg}$ ) is associated with an increased risk of mortality following surgical AVR. The presence of very low gradient is probably a composite marker of more severe low-flow state (i.e., more severely reduced stroke volume index) and/or of less severe stenosis. Furthermore, in these patients, the absence of LV flow reserve, as documented by a percent increase in stroke volume $<20 \%$ during DSE, is a predictor of perioperative mortality following AVR. Indeed, previous studies have reported that patients with no flow reserve, who represent approximately $30-40 \%$ of patients with LF-LG AS, have an operative mortality of between 22 and $33 \%$ compared to $5-8 \%$ in patients with flow reserve $\mathrm{e}^{14,17,38}$. Hence, the absence of flow reserve is useful for operative risk stratification in patients with LF-LG AS prior to surgical AVR but, on the other hand, this factor does predict long-term mortality or recovery of LVEF following $\mathrm{AVR}^{39}$. Other DSE parameters of valve or $\mathrm{LV}$ function, including a projected AVA $<1.2 \mathrm{~cm}^{2}$ and peak stress LVEF $<35 \%$ during DSE, have been shown to predict long-term mortality both in patients treated surgically and in those treated conservatively ${ }^{18,29}$. The peak stress LVEF is probaly a composite marker of resting LV function and contractile reserve with DSE. The fact that the best cut point of projected AVA to predict outcomes (i.e., $1.2 \mathrm{~cm}^{2}$ ) is higher than that to identify TS AS (i.e., $1.0 \mathrm{~cm}^{2}$ ) suggests that the increased load imposed by a moderate AS may be tolerated well by a normal ventricle but poorly by a failing ventricle.

Recent studies suggest that echocardiographic parameters of LV longitudinal systolic function, including mitral annulus displacement or global longitudinal strain and strain rate, are superior to LVEF to quantify the extent of myocardial impairment and to predict outcomes in patients with classic or paradoxical LF-LG ${ }^{21,40,41}$. These parameters are surrogate markers of the severity of subendocardial fibrosis and they appear to be among the most promising imaging biomarkers in LF-LG AS. Given that platforms from different ultrasound system vendors may provide somewhat different results for myocardial strain, there is a need for the realisation of multicentre studies using a common and vendor-independent platform in order to establish the best cut points of global longitudinal strain to predict outcome and response to therapy in patients with LF-LG AS.

The quantification of myocardial fibrosis by cardiac magnetic resonance (CMR) imaging also appears to be a very promising approach to enhance risk stratification in patients with classic or paradoxical LF-LG AS ${ }^{21,42}$. Patients with extensive myocardial fibrosis have poor outcomes under conservative therapy but high operative mortality and limited regression of symptoms following surgical $\mathrm{AVR}^{21,42}$. Besides focal fibrosis which can be assessed by late gadolinium enhancement, it may also be important and probably more relevant to assess diffuse fibrosis using contrast-enhanced T1-mapping techniques in these patients with LF-LG AS. The main limitation of CMR is the high cost and often limited availability of this modality as well as the lack of standardisation of the imaging sequence and criteria that should be used to quantify myocardial fibrosis. Additional studies are needed to establish further and refine the role of the quantification of LV longitudinal strain by speckle tracking and of myocardial fibrosis by CMR in patients with LF-LG AS.

\section{Therapeutic management}

As underlined in the two previous sections, multimodality imaging is useful to determine stenosis severity and operative risk, which are key pieces of information to guide therapeutic management of LF-LG AS (Figure 3). Cardiac catheterisation and angiography do not provide any additional information on aortic valve or LV function besides that obtained by DSE, MDCT or CMR. However, cardiac catheterisation is useful to detect and document the presence of significant obstructive coronary disease, which may dictate the need for a revascularisation procedure. Table 2 presents the recommendations of the ESC/EACTS and ACC/AHA guidelines with regard to the indication for AVR in patients with classic and paradoxical LF-LG AS.

\section{Classic LF-LG AS}

Patients with classic LF-LG AS who have evidence of TS AS and LV flow reserve should undergo surgical AVR (Figure 3, Table 2). Coronary artery bypass graft surgery should be performed concomitantly in patients with clinical indications for revascularisation. However, in patients with no flow reserve or with other comorbidities associated with high surgical risk, transcatheter AVR may provide a good alternative to surgery (Figure 3$)^{35,36,43-45}$. In patients in whom recovery of LV function as well as the regression of symptoms after procedure are uncertain (e.g., patients with extensive myocardial fibrosis, severe frailty, and/or severe comorbidities, such as oxygen-dependent chronic obstructive pulmonary disease $)^{21}$, a staged approach with balloon valvuloplasty first followed by surgical or transcatheter AVR six months later (if LV function/symptoms improve) may be the preferred strategy. In the PARTNER I trial cohort A (high risk), there was no significant difference between transcatheter and surgical AVR in the subset of 


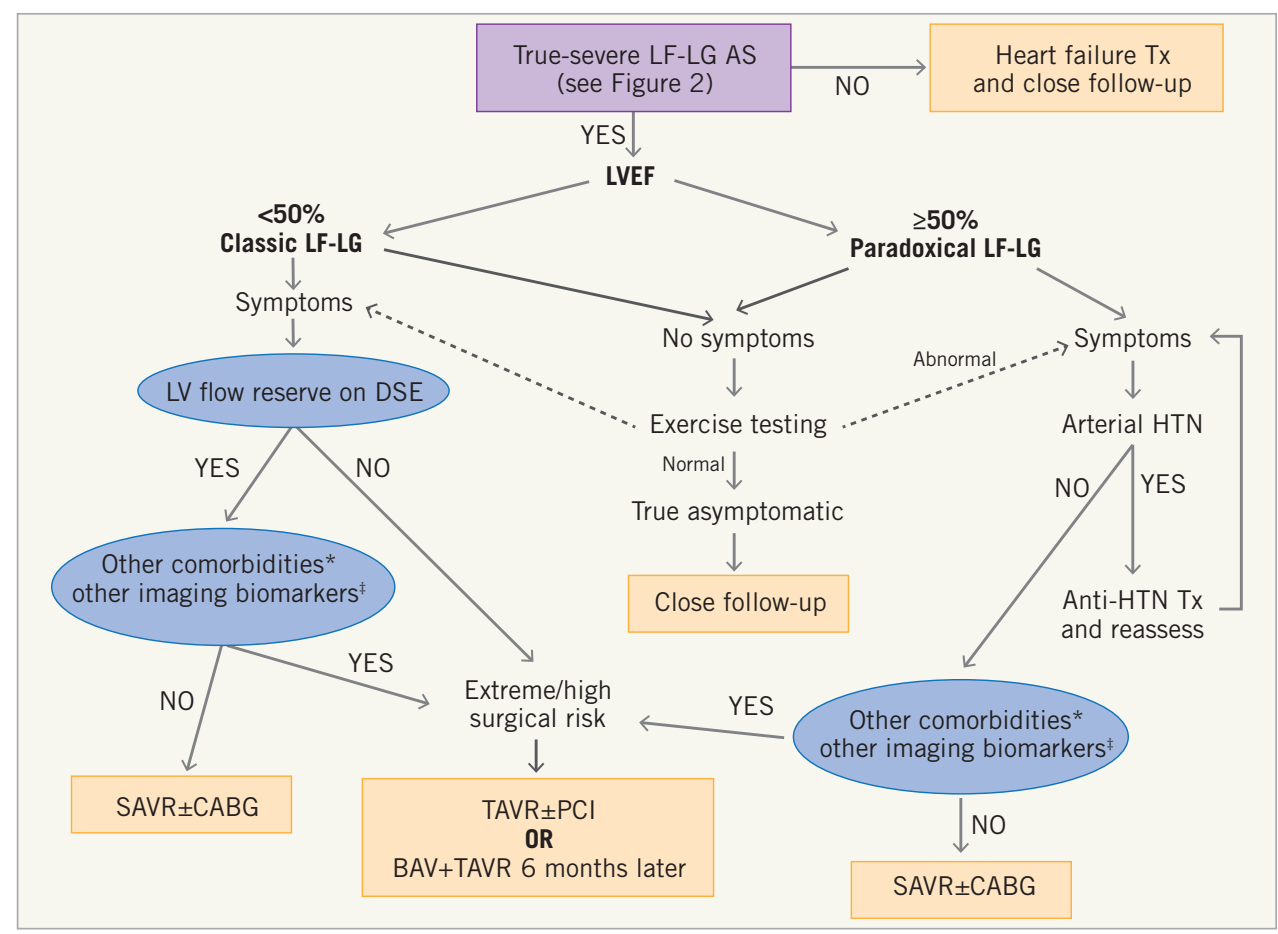

Figure 3. Algorithm for the therapeutic management of patients with low-flow, low-gradient aortic stenosis. *Comorbidities associated with high/extreme surgical risk. FEmerging biomarkers obtained by non-invasive multimodality imaging (DSE, MDCT and CMR), including severe myocardial fibrosis, severely reduced global longitudinal strain, severe LV restrictive diastolic pattern. These biomarkers also include the presence of a small aortic annulus $(<21 \mathrm{~mm})$ as this factor may increase the surgical risk as well as the risk of prosthesis-patient mismatch. BAV: balloon aortic valvuloplasty; CABG: coronary artery bypass graft surgery; HTN: hypertension; PCI: percutaneous coronary intervention; Tx: treatment; SAVR: surgical aortic valve replacement; TAVR: transcatheter aortic valve replacement

patients with classic LF-LG AS ${ }^{36}$. However, patients with no flow reserve (i.e., patients with higher surgical risk) were excluded from this trial, therefore introducing a selection bias. In a non-randomised study including both LF-LG patients with flow reserve and those with no flow reserve, transcatheter AVR was associated with better and faster recovery of $\mathrm{LVEF}^{43}$.
Patients with classic LF-LG and evidence of PS AS (Figure 2) should be treated conservatively, but they require aggressive heart failure therapy and close follow-up (Figure 3 ) $^{28}$. However, these patients may need AVR if the stenosis progresses to the severe stage during follow-up and/or if medical therapy fails to improve symptoms.

Table 2. Guideline recommendations for aortic valve replacement in patients with low-flow, low-gradient aortic stenosis.

\begin{tabular}{|c|c|c|c|}
\hline Guidelines & Recommendation for AVR & Class & Level $^{\ddagger}$ \\
\hline \multicolumn{4}{|c|}{ Classic low-flow, low-gradient AS* } \\
\hline ESC/EACTS 2012 & $\begin{array}{l}\text { AVR should be considered in symptomatic patients with severe AS, low-flow, } \\
\text { low-gradient with reduced LVEF, and evidence of flow reserve. }\end{array}$ & Ila & C \\
\hline ESC/EACTS 2012 & $\begin{array}{l}\text { AVR may be considered in symptomatic patients with severe AS low-flow, low- } \\
\text { gradient, and LV dysfunction without flow reserve. }\end{array}$ & $\mathrm{IIb}$ & C \\
\hline ACC/AHA 2014 & $\begin{array}{l}\text { AVR is reasonable in symptomatic patients with low LVEF, low-flow/low-gradient } \\
\text { severe AS with a DSE that shows a mean gradient } \geq 40 \mathrm{mmHg} \text { with an AVA } \leq 1.0 \mathrm{~cm}^{2} \\
\text { at any dobutamine dose. }\end{array}$ & Ila & B \\
\hline \multicolumn{4}{|c|}{ Paradoxical low-flow, low-gradient AS" } \\
\hline ESC/EACTS 2012 & $\begin{array}{l}\text { AVR should be considered in symptomatic patients with low-flow, low-gradient } \\
(<40 \mathrm{mmHg}) \text { AS with normal LVEF only after careful confirmation of severe AS. }\end{array}$ & Ila & C \\
\hline ACC/AHA 2014 & $\begin{array}{l}\text { AVR is reasonable in symptomatic patients who have low-flow, low-gradient severe } \\
\text { AS who are normotensive and have an LVEF } \geq 50 \% \text { if clinical, haemodynamic and } \\
\text { anatomic data support valve obstruction as the most likely cause of symptoms. }\end{array}$ & Ila & C \\
\hline \multicolumn{4}{|c|}{$\begin{array}{l}\text { This table summarises the recommendations presented in the ESC/EACTS and ACC/AHA guidelines for the indication of AVR in low-flow, low-gradient } \\
\text { AS. }{ }^{*} \text { Classic low-flow, low-gradient AS is defined as an LVEF }<50 \% \text {, an AVA }<1.0 \mathrm{~cm}^{2} \text {, and a mean gradient }<40 \mathrm{mmHg} \text {. TParadoxical low-flow, } \\
\text { low-gradient AS is defined as LVEF } \geq 50 \% \text {, AVA }<1.0 \mathrm{~cm}^{2} \text {, indexed AVA }<0.6 \mathrm{~cm}^{2} / \mathrm{m}^{2} \text {, mean gradient }<40 \mathrm{mmHg} \text {, and indexed stroke volume } \\
<35 \mathrm{~mL} / \mathrm{m}^{2} \text {. "Level of evidence. AS: aortic stenosis; AVA: aortic valve area; AVR: aortic valve replacement; LVEF: left ventricular ejection fraction }\end{array}$} \\
\hline
\end{tabular}




\section{Paradoxical LF-LG AS}

The ESC/EACTS and ACC/AHA guidelines ${ }^{2,3}$ recommend AVR (Class IIa) in patients with paradoxical LF-LG AS if they fulfil the following conditions (Table 2): i) presence of symptoms; ii) confirmation of TS AS; and iii) symptoms most likely related to AS. Moreover, given that arterial hypertension is frequent in patients with paradoxical LF-LG and that it may contribute to the low-flow state, the AVA gradient discordance and the symptoms, the ACC/AHA guidelines ${ }^{2}$ recommend first to optimise antihypertensive therapy and then to reassess stenosis severity and symptoms once blood pressure has been normalised before eventually considering AVR.

Paradoxical low-flow AS is often associated with several factors (i.e., pronounced concentric remodelling, advanced myocardial fibrosis, severe diastolic function, severely impaired LV systolic longitudinal strain, small aortic annulus, etc.) which may increase the risk of perioperative mortality as well as the risk of prosthesis-patient mismatch following surgical $\mathrm{AVR}^{4,8,21}$. Transcatheter AVR may help to reduce both the operative risk and the incidence of prosthesis-patient mismatch in these patients ${ }^{36,46}$. Hence, as in patients with classic LF-LG AS, transcatheter AVR may provide a valuable alternative to surgical AVR in patients with paradoxical LF-LG AS, particularly if they have the risk factors mentioned above (Figure 3). In this regard, the investigators of the PARTNER IA trial revealed that patients with paradoxical LF-LG AS appear to have better short-term survival with transcatheter AVR compared to surgical $\mathrm{AVR}^{36}$. However, these patients may poorly tolerate even a mild degree of acute aortic regurgitation due to their restrictive physiology. Hence, if transcatheter AVR is considered for the treatment of paradoxical LF-LG severe AS, it is essential to avoid any degree of paravalvular regurgitation. Additional studies are needed to determine which is the best procedure, i.e., surgical versus transcatheter AVR, in the different subsets of patients with classic or paradoxical LF-LG severe AS.

\section{Conclusion}

A multimodality imaging approach, including comprehensive resting echocardiography, DSE, and/or MDCT, is the key to successful management of patients with classic or paradoxical LF-LG AS, who represent a highly challenging subset from both a diagnostic and a therapeutic standpoint. This approach is indeed essential for confirmation of stenosis severity, risk stratification, and therapeutic decision making in these patients. DSE and AVC quantification by MDCT provide important complementary information that is crucial to differentiate TS from PS AS and therefore to select the most appropriate therapy (i.e., AVR vs. medical) for a given patient. The assessment of LV flow reserve by DSE is useful to stratify the operative risk and guide decision making between surgical and transcatheter AVR. Other imaging biomarkers, such as the global LV longitudinal strain measured at rest and during DSE or the amount of myocardial fibrosis assessed by CMR, may provide incremental information for risk stratification and therapeutic management in LF-LG AS, but additional studies are needed to validate and refine these emerging biomarkers further.

\section{Conflict of interest statement}

P. Pibarot received research grants from Edwards Lifesciences for Echocardiography Core Laboratory Analyses in transcatheter valve therapy studies. The other author has no conflicts of interest to declare.

\section{References}

1. Baumgartner $\mathrm{H}$, Hung $\mathrm{J}$, Bermejo $\mathrm{J}$, Chambers $\mathrm{JB}$, Evangelista A, Griffin BP, Iung B, Otto CM, Pellikka PA, Quiñones M; American Society of Echocardiography; European Association of Echocardiography. Echocardiographic assessment of valve stenosis: EAE/ASE recommendations for clinical practice. $J$ Am Soc Echocardiogr. 2009;22:1-23.

2. Nishimura RA, Otto CM, Bonow RO, Carabello BA, Erwin JP 3rd, Guyton RA, O'Gara PT, Ruiz CE, Skubas NJ, Sorajja P, Sundt TM 3rd, Thomas JD; American College of Cardiology/ American Heart Association Task Force on Practice Guidelines. 2014 AHA/ACC guideline for the management of patients with valvular heart disease: executive summary: a report of the American College of Cardiology/American Heart Association Task Force on Practice Guidelines. J Am Coll Cardiol. 2014;63:2438-88.

3. Joint Task Force on the Management of Valvular Heart Disease of the European Society of Cardiology (ESC); European Association for Cardio-Thoracic Surgery (EACTS), Vahanian A, Alfieri O, Andreotti F, Antunes MJ, Barón-Esquivias G, Baumgartner H, Borger MA, Carrel TP, De Bonis M, Evangelista A, Falk V, Iung B, Lancellotti P, Pierard L, Price S, Schäfers HJ, Schuler G, Stepinska J, Swedberg K, Takkenberg J, Von Oppell UO, Windecker S, Zamorano JL, Zembala M. Guidelines on the management of valvular heart disease (version 2012). Eur Heart $J$. 2012;33:2451-96.

4. Dumesnil JG, Pibarot P, Carabello B. Paradoxical low flow and/or low gradient severe aortic stenosis despite preserved left ventricular ejection fraction: implications for diagnosis and treatment. Eur Heart J. 2010;31:281-9.

5. Lancellotti P, Magne J, Donal E, Davin L, O'Connor K, Rosca M, Szymanski C, Cosyns B, Piérard LA. Clinical outcome in asymptomatic severe aortic stenosis: insights from the new proposed aortic stenosis grading classification. $J$ Am Coll Cardiol. 2012;59:235-43.

6. Clavel MA, Messika-Zeitoun D, Pibarot P, Aggarwal SR, Malouf J, Araoz PA, Michelena HI, Cueff C, Larose E, Capoulade R, Vahanian A, Enriquez-Sarano M. The complex nature of discordant severe calcified aortic valve disease grading: new insights from combined Doppler echocardiographic and computed tomographic study. J Am Coll Cardiol. 2013;62:2329-38.

7. Minners J, Allgeier M, Gohlke-Baerwolf C, Kienzle RP, Neumann FJ, Jander N. Inconsistent grading of aortic valve stenosis by current guidelines: haemodynamic studies in patients with apparently normal left ventricular function. Heart. 2010;96: 1463-8.

8. Hachicha Z, Dumesnil JG, Bogaty P, Pibarot P. Paradoxical low flow, low gradient severe aortic stenosis despite preserved 
ejection fraction is associated with higher afterload and reduced survival. Circulation. 2007;115:2856-64.

9. Barasch E, Fan D, Chukwu EO, Han J, Passick M, Petillo F, Norales A, Reichek N. Severe isolated aortic stenosis with normal left ventricular systolic function and low transvalvular gradients: pathophysiologic and prognostic insights. J Heart Valve Dis. 2008; 17:81-8.

10. Michelena HI, Margaryan E, Miller FA, Eleid M, Maalouf J, Suri R, Messika-Zeitoun D, Pellikka PA, Enriquez-Sarano M. Inconsistent echocardiographic grading of aortic stenosis: is the left ventricular outflow tract important? Heart. 2013;99:921-31.

11. Rossi A, Tomaino M, Golia G, Anselmi M, Fuca G, Zardini P. Echocardiographicprediction of clinicaloutcomeinmedically treated patients with aortic stenosis. Am Heart J. 2000;140:766-71.

12. Clavel MA, Dumesnil JG, Capoulade R, Mathieu P, Sénéchal M, Pibarot P. Outcome of patients with aortic stenosis, small valve area and low-flow, low-gradient despite preserved left ventricular ejection fraction. J Am Coll Cardiol. 2012;60:1259-67.

13. Schwammenthal E, Vered Z, Moshkowitz Y, Rabinowitz B, Ziskind Z, Smolinski AK, Feinberg MS. Dobutamine echocardiography in patients with aortic stenosis and left ventricular dysfunction: predicting outcome as a function of management strategy. Chest. 2001;119:1766-77.

14. Connolly HM, Oh JK, Schaff HV, Roger VL, Osborn SL, Hodge DO, Tajik AJ. Severe aortic stenosis with low transvalvular gradient and severe left ventricular dysfunction: result of aortic valve replacement in 52 patients. Circulation. 2000;101:1940-6.

15. Kulik A, Burwash IG, Kapila V, Mesana TG, Ruel M. Longterm outcomes after valve replacement for low-gradient aortic stenosis: impact of prosthesis-patient mismatch. Circulation. 2006; 114:I553-8.

16. deFilippi CR, Willett DL, Brickner E, Appleton CP, Yancy CW, Eichhorn EJ, Grayburn PA. Usefulness of dobutamine echocardiography in distinguishing severe from nonsevere valvular aortic stenosis in patients with depressed left ventricular function and low transvalvular gradients. Am J Cardiol. 1995;75:191-4.

17. Monin JL, Quere JP, Monchi M, Petit H, Baleynaud S, Chauvel C, Pop C, Ohlmann P, Lelguen C, Dehant P, Tribouilloy C, Guéret P. Low-gradient aortic stenosis: operative risk stratification and predictors for long-term outcome: a multicenter study using dobutamine stress hemodynamics. Circulation. 2003;108:319-24.

18. Clavel MA, Fuchs C, Burwash IG, Mundigler G, Dumesnil JG, Baumgartner H, Bergler-Klein J, Beanlands RS, Mathieu P, Magne J, Pibarot P. Predictors of outcomes in low-flow, low-gradient aortic stenosis: results of the multicenter TOPAS Study. Circulation. 2008;118:S234-42.

19. Pibarot P, Dumesnil JG. Low-flow, low-gradient aortic stenosis with normal and depressed left ventricular ejection fraction. J Am Coll Cardiol. 2012;60:1845-53.

20. Pai RG, Varadarajan P, Razzouk A. Survival benefit of aortic valve replacement in patients with severe aortic stenosis with low ejection fraction and low gradient with normal ejection fraction. Ann Thorac Surg. 2008;86:1781-9.
21. Herrmann S, Stork S, Niemann M, Lange V, Strotmann JM, Frantz S, Beer M, Gattenlöhner S, Voelker W, Ertl G, Weidemann F. Low-gradient aortic valve stenosis myocardial fibrosis and its influence on function and outcome. J Am Coll Cardiol. 2011;58:402-12.

22. Lancellotti P, Donal E, Magne J, O'Connor K, Moonen ML, Cosyns B, Pierard LA. Impact of global left ventricular afterload on left ventricular function in asymptomatic severe aortic stenosis: a two-dimensional speckle-tracking study. Eur $J$ Echocardiogr. 2010;11:537-43.

23. Pibarot P, Dumesnil JG. Aortic stenosis suspected to be severe despite low gradients. Circ Cardiovasc Imaging. 2014;7:545-51.

24. Roger VL. Left ventricular function in aortic stenosis: a clinical review. J Heart Valve Dis. 1995;4:S230-5.

25. Grayburn PA, Eichhorn EJ. Dobutamine challenge for lowgradient aortic stenosis. Circulation. 2002;106:763-5.

26. Nishimura RA, Grantham JA, Connolly HM, Schaff HV, Higano ST, Holmes DR Jr. Low-output, low-gradient aortic stenosis in patients with depressed left ventricular systolic function: the clinical utility of the dobutamine challenge in the catheterization laboratory. Circulation. 2002;106:809-13.

27. Clavel MA, Ennezat PV, Maréchaux S, Dumesnil JG, Capoulade R, Hachicha Z, Mathieu P, Bellouin A, Bergeron S, Meimoun P, Arsenault M, Le Tourneau T, Pasquet A, Couture C, Pibarot P. Stress echocardiography to assess stenosis severity and predict outcome in patients with paradoxical low-flow, low-gradient aortic stenosis and preserved LVEF. JACC Cardiovasc Imaging. 2013;6:175-83.

28. Fougères É, Tribouilloy C, Monchi M, Petit-Eisenmann H, Baleynaud S, Pasquet A, Chauvel C, Metz D, Adams C, Rusinaru D, Guéret P, Monin JL. Outcomes of pseudo-severe aortic stenosis under conservative treatment. Eur Heart J. 2012;33:2426-33.

29. Clavel MA, Burwash IG, Mundigler G, Dumesnil JG, Baumgartner H, Bergler-Klein J, Sénéchal M, Mathieu P, Couture C, Beanlands R, Pibarot P. Validation of conventional and simplified methods to calculate projected valve area at normal flow rate in patients with low flow, low gradient aortic stenosis: the multicenter TOPAS (True or Pseudo Severe Aortic Stenosis) study. J Am Soc Echocardiogr. 2010;23:380-6.

30. Blais C, Burwash IG, Mundigler G, Dumesnil JG, Loho N, Rader F, Baumgartner H, Beanlands RS, Chayer B, Kadem L, Garcia D, Durand LG, Pibarot P. Projected valve area at normal flow rate improves the assessment of stenosis severity in patients with low-flow, low-gradient aortic stenosis: the multicenter TOPAS (Truly or Pseudo Severe Aortic Stenosis) study. Circulation. 2006;113:711-21.

31. Blais C, Pibarot P, Dumesnil JG, Garcia D, Chen D, Durand LG. Comparison of valve resistance with effective orifice area regarding flow dependence. Am J Cardiol. 2001;88:45-52.

32. Messika-Zeitoun D, Aubry MC, Detaint D, Bielak LF, Peyser PA, Sheedy PF, Turner ST, Breen JF, Scott C, Tajik AJ, Enriquez-Sarano M. Evaluation and clinical implications of aortic valve calcification measured by electron-beam computed tomography. Circulation. 2004;110:356-62. 
33. Cueff C, Serfaty JM, Cimadevilla C, Laissy JP, Himbert D, Tubach F, Duval X, Iung B, Enriquez-Sarano M, Vahanian A, Messika-Zeitoun D. Measurement of aortic valve calcification using multislice computed tomography: correlation with haemodynamic severity of aortic stenosis and clinical implication for patients with low ejection fraction. Heart. 2011;97:721-6.

34. Aggarwal SR, Clavel MA, Messika-Zeitoun D, Cueff C, Malouf J, Araoz PA, Mankad R, Michelena H, Vahanian A, Enriquez-Sarano M. Sex differences in aortic valve calcification measured by multidetector computed tomography in aortic stenosis. Circ Cardiovasc Imaging. 2013;6:40-7.

35. Le Ven F, Freeman M, Webb J, Clavel MA, Wheeler M, Dumont É, Thompson C, De Larochellière R, Moss R, Doyle D, Ribeiro HB, Urena M, Nombela-Franco L, Rodés-Cabau J, Pibarot P. Impact of low flow on the outcome of high risk patients undergoing transcatheter aortic valve replacement. $J$ Am Coll Cardiol. 2013;62:782-8.

36. Herrmann HC, Pibarot P, Hueter I, Gertz ZM, Stewart WJ, Kapadia S, Tuzcu EM, Babaliaros V, Thourani V, Szeto WY, Bavaria JE, Kodali S, Hahn RT, Williams M, Miller DC, Douglas PS, Leon MB. Predictors of mortality and outcomes of therapy in low-flow severe aortic stenosis: a Placement of Aortic Transcatheter Valves (PARTNER) trial analysis. Circulation. 2013;127:2316-26.

37. Ozkan A, Hachamovitch R, Kapadia SR, Tuzcu EM, Marwick TH. Impact of aortic valve replacement on outcome of symptomatic patients with severe aortic stenosis with low gradient and preserved left ventricular ejection fraction. Circulation. 2013; 128:622-31.

38. Tribouilloy C, Levy F, Rusinaru D, Guéret P, PetitEisenmann H, Baleynaud S, Jobic Y, Adams C, Lelong B, Pasquet A, Chauvel C, Metz D, Quéré JP, Monin JL. Outcome after aortic valve replacement for low-flow/low-gradient aortic stenosis without contractile reserve on dobutamine stress echocardiography. $J$ Am Coll Cardiol. 2009;53:1865-73.

39. Quere JP, Monin JL, Levy F, Petit H, Baleynaud S, Chauvel C, Pop C, Ohlmann P, Lelguen C, Dehant P, Gueret P, Tribouilloy C. Influence of preoperative left ventricular contractile reserve on postoperative ejection fraction in low-gradient aortic stenosis. Circulation. 2006;113:1738-44.

40. Bartko PE, Heinze G, Graf S, Clavel MA, Khorsand A, BerglerKlein J, Burwash IG, Dumesnil JG, Sénéchal M, Baumgartner H, Rosenhek R, Pibarot P, Mundigler G. Two-dimensional strain for the assessment of left ventricular function in low flow-low gradient aortic stenosis, relationship to hemodynamics and outcome: a substudy of the multicenter TOPAS study. Circ Cardiovasc Imaging. 2013;6:268-76.

41. Lancellotti P, Moonen M, Magne J, O’Connor K, Cosyns B, Attena E, Donal E, Pierard L. Prognostic effect of long-axis left ventricular dysfunction and B-type natriuretic peptide levels in asymptomatic aortic stenosis. Am J Cardiol. 2010;105:383-8.

42. Weidemann F, Herrmann S, Störk S, Niemann M, Frantz S, Lange V, Beer M, Gattenlöhner S, Voelker W, Ertl G, Strotmann JM. Impact of myocardial fibrosis in patients with symptomatic severe aortic stenosis. Circulation. 2009;120:577-84.

43. Clavel MA, Webb JG, Rodés-Cabau J, Masson JB, Dumont E, De Larochellière $\mathrm{R}$, Doyle $\mathrm{D}$, Bergeron $\mathrm{S}$, Baumgartner $\mathrm{H}$, Burwash IG, Dumesnil JG, Mundigler G, Moss R, Kempny A, Bagur R, Bergler-Klein J, Gurvitch R, Mathieu P, Pibarot P. Comparison between transcatheter and surgical prosthetic valve implantation in patients with severe aortic stenosis and reduced left ventricular ejection fraction. Circulation. 2010;122:1928-36.

44. Gotzmann M, Lindstaedt M, Bojara W, Ewers A, Mugge A. Clinical outcome of transcatheter aortic valve implantation in patients with low-flow, low gradient aortic stenosis. Catheter Cardiovasc Interv. 2012;79:693-701.

45. Bauer F, Coutant V, Bernard M, Stepowski D, Tron C, Cribier A, Bessou JP, Eltchaninoff H. Patients with severe aortic stenosis and reduced ejection fraction: earlier recovery of left ventricular systolic function after transcatheter aortic valve implantation compared with surgical valve replacement. Echocardiography. 2013;30:865-70.

46. Pibarot P, Weissman NJ, Stewart WJ, et al. Incidence and Sequelae of Prosthesis-Patient Mismatch in Transcatheter versus Surgical Valve Replacement in High-Risk Patients with Severe Aortic Stenosis - A PARTNER Trial Cohort A Analysis. J Am Coll Cardiol. 2014; In Press.

\section{Online data supplement}

Moving image 1. Representative example of echocardiographic images of the LV cavity and aortic valve in the parasternal longaxis view for patients with normal flow, high gradient.

Moving image 2. Representative example of echocardiographic images of the LV cavity and aortic valve in the parasternal longaxis view for patients with classic low flow, low gradient.

Moving image 3. Representative example of echocardiographic images of the LV cavity and aortic valve in the parasternal longaxis view for patients with paradoxical low flow, low gradient. 